\title{
Suicide and suicide attempts among women in the Manitoba Mothers and Fetal Alcohol Spectrum Disorder cohort: a retrospective matched analysis using linked administrative data
}

\author{
Deepa Singal MSc, Marni Brownell PhD, Dan Chateau PhD, Elizabeth Wall-Wieler MSc, \\ Sally Longstaffe MD, Ana Hanlon-Dearman MD, Leslie L. Roos PhD
}

\section{Abstract}

Background: Women who give birth to children with fetal alcohol spectrum disorder (FASD) may be at increased risk for suicide; however, there are few data in this area. The objective of this study was to compare rates of suicide between women who had given birth to children with FASD and women who had not given birth to children with FASD during critical periods in their lives, including before pregnancy, during pregnancy, during the postpartum period (maternal death) and until the end of the study period.

Methods: We conducted a retrospective cohort analysis of women with children born in Manitoba between Apr. 1, 1984, and Mar. 31, 2012 in whom FASD was diagnosed between Apr. 1, 1999, and Mar. 31, 2012, with follow-up until Dec. 1, 2013 (FASD group; $n=702$ ). We generated a comparison group of women who had not given birth to children with FASD $(n=2097)$, matched up to 1:3 on date of birth of the index child, socioeconomic status and region of residence. We used linked administrative data to investigate suicide attempt and completion rates in the 2 groups. Regression modelling produced relative rates (RRs) adjusted for socioeconomic status and age at birth of the index child and was used to assess suicide risk.

Results: The 2799 participants produced 40390.21 person-years until the end of the study period. Compared to the comparison group, the FASD group had higher rates of suicide completion (adjusted RR 6.20 [95\% confidence interval (Cl) 2.36-16.31]), a higher number of women who attempted suicide after the postpartum period until the end of the study period (adjusted RR 4.62 [95\% Cl 2.53-8.43]) and a higher number of attempts after the postpartum period until the end of the study period (adjusted RR 3.92 [95\% Cl 2.30-6.09]).

Interpretation: This study identified a group of women with increased rates of social complexities, mental disorders and alcohol use, which places them at risk for suicide. Interventions are needed that screen for suicidal behaviour in women who are at high risk to consume alcohol during pregnancy and have mental disorders.

uicide is the most common cause of maternal death in developed countries. ${ }^{1}$ Maternal death is defined as death occurring from direct (obstetric complications) or indirect (conditions not directly related to obstetric) causes between 42 and 356 days post partum. ${ }^{1,2}$ Few Canadian studies have examined the rates of maternal death due to suicide, and there is no individual-level investigation of maternal deaths to identify contributing factors. ${ }^{3}$ Identifying groups of vulnerable women who are at risk for suicidal behaviour is crucial for the development of effective prevention strategies.

Women who give birth to children with fetal alcohol spectrum disorder (FASD) may be at increased risk for suicide. These women have histories of frequent, heavy alcohol use, and there is a strong association between alcohol dependence and suicide. ${ }^{4-10}$ They also have complex histories that may place them at risk for suicide, including abuse, poverty, substance use disorders, intergenerational trauma ${ }^{11-16}$ and high rates of psychiatric disorders. ${ }^{17-20}$ These women often experience stigma and are afraid of losing their children to child

Competing interests: None declared.

This article has been peer reviewed.

Correspondence to: Deepa Singal, DeepaKapoorSingal@gmail.com CMAJ Open 2017. DOI:10.9778/cmajo.20160127 
welfare systems, ${ }^{13,21-23}$ which can lead to hopelessness and helplessness, strong risk factors for suicidal behaviour. ${ }^{10,24}$

The objective of this study was to compare suicide rates among women who had given birth to a child(ren) with FASD and those who had not given birth to a child(ren) with FASD during critical periods in their lives, including before pregnancy, during pregnancy, during the postpartum period (maternal death) and until the end of the study period. The identification of suicide risk during critical periods in the lives of women with children with FASD may aid in the development of targeted prevention and support programs. It is important to note that we are not drawing associations between the diagnosis of FASD in a child and maternal suicide, as FASD may be diagnosed years before the suicide attempt. We are using the FASD diagnosis to identify a potentially vulnerable group of women with alcohol use issues who may require targeted, multifactorial interventions to decrease suicide risk.

\section{Methods}

\section{Study setting and design}

This was a retrospective analysis of the Manitoba Mothers and FASD cohort, ${ }^{25}$ which consists of mothers of children born in Manitoba between Apr. 1, 1984, and Mar. 31, 2012 in whom FASD was diagnosed between Apr. 1, 1999, and Mar. 31, 2012, with follow-up until Dec. 1, 2013. We chose 1999 as the first year to ascertain FASD diagnosis because this was when accurate FASD diagnosis data became available. We investigated suicide attempts in the 5 years before and up to 1 year after the birth of the child until the end of the study period, resulting in a total study period of Apr. 1, 1979, to Dec. 1, 2013.

\section{Data sources}

We used administrative data from the Manitoba Population Research Data Repository (MPRDR), housed at the Manitoba Centre for Health Policy (MCHP), and clinical assessment data from the Manitoba FASD Centre, a referral/diagnostic centre for FASD in the province, as the primary data sources. Deidentified health records are transferred to the MCHP from the government department that administers the universal health insurance program for the province and contain scrambled identifiers that allow for linkages across multiple databases. Linkages are performed with the use of de-identified, unique personal health identification numbers. Data on suicide attempts and completions as well as all-cause mortality from Manitoba Vital Certificates of mortality include cause of death, physician reimbursement claims and hospital discharge abstracts (Appendix 1, available at www.cmajopen.ca/ content/5/3/E646/suppl/DC1). Data in the MPRDR have been widely used for health research, and the reliability of the databases has been well established. ${ }^{26-33}$ The MPRDR contains information for all people eligible or registered for health insurance benefits through the Manitoba Health Insurance Plan. The MPRDR identifies all residents in the province except those insured by the federal government (such as military personnel and federal inmates), who account for less than $0.5 \%$ of the provincial population).

\section{Cohort formulation}

Women were drawn from the entire population of women with a child(ren) born in Manitoba between Apr. 1, 1984, and Mar. 31, 2012. Two groups were generated: women who had given birth to a child with FASD (FASD group), and a comparison group of women who had not given birth to a child with FASD (Figure 1).

\section{FASD group}

We used clinical data from the Manitoba FASD Centre to ascertain all children and youth (birth to $21 \mathrm{yr}$ ) in whom FASD had been diagnosed between 1999 and 2012. The mean age at diagnosis was 8.2 (standard deviation 4.89) years, range birth to 26.43 years. The Manitoba FASD Centre database was linked to administrative data from the MPRDR to identify these children's birth mothers. Only women who could be linked to their children, who had postal code information and who were Manitoba residents registered to receive health care in the province and covered from the birth of their child until December 2013 were included.

\section{Comparison group}

Women whose children did not receive an FASD diagnosis from the Manitoba FASD Centre, who had no record of alcohol use during pregnancy and whose children had no evidence of FASD from the MPRDR were drawn from the MPRDR and were matched with up to 3 women in the FASD group on month of birth of the index child, socioeconomic status and region of residence. To decrease the likelihood that women in the comparison group had children with undiagnosed FASD, we used the following exclusion criteria: 1) assessment of any of the woman's children at the Manitoba FASD Centre, 2) a child who had a diagnosis of FASD as recorded in hospital or physician claims data with the following International Classification of Diseases (ICD) codes: a hospital visit with ICD-9-CM code 760.71 or ICD-10-CCA code 86.0 , or a physician visit with any ICD-9 code 760,3 ) a child who had prescriptions for psychostimulants or risperidone, 4) a child with a diagnosis of attention-deficit/hyperactivity disorder (owing to the high comorbidity of FASD and attention-deficit/hyperactivity disorder diagnoses $\left.{ }^{34,35}\right)$, 5 ) involvement in the InSight Mentoring Program (a program that provides support for women with alcohol and substance abuse issues), 6) a history of substance abuse disorder (including alcohol) during pregnancy as indicated in the physician and hospital claims, 7) indication of use of alcohol during pregnancy on the newborn risk screen and 8) a child who had received special education funding, indicating severe to profound disability.

\section{Suicidal behaviour}

\section{Attempts}

In both groups, we analyzed the total number of suicide attempts (defined as any hospital admission with any diagnosis of a suicide attempt, including accidental and self-inflicted 
poisoning, poisoning with undetermined intent and selfinflicted injuries; see Appendix 2, available at www.cmajopen. $\mathrm{ca} /$ content/5/3/E646/suppl/DC1, for ICD codes) and the total number of women who attempted suicide at least once during the 5 years before the birth of the index child, during pregnancy, during the postpartum period (birth to 1 year after birth) and from 366 days after birth to the end of the study period.

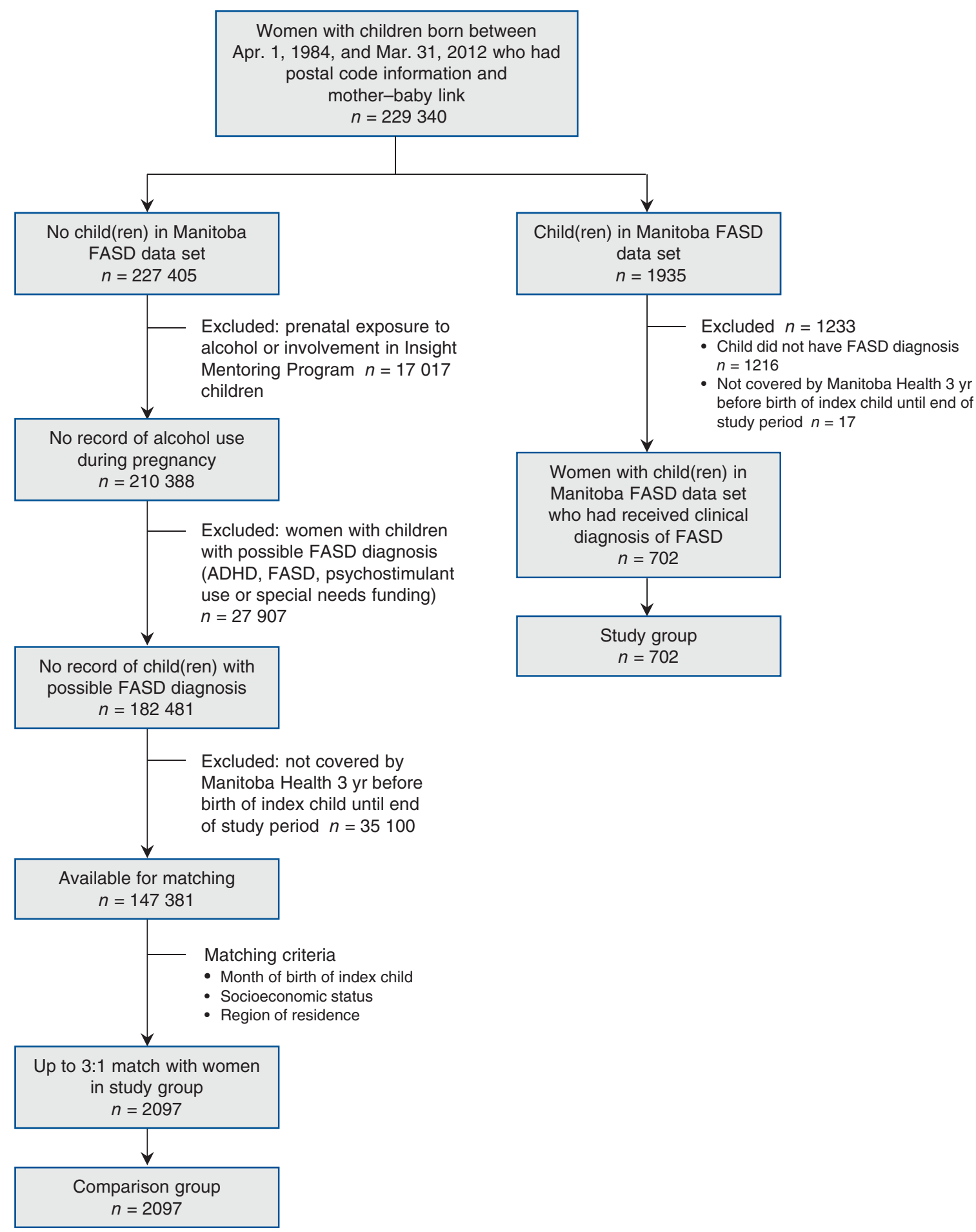

Figure 1: Study cohort selection. Note: ADHD = attention-deficit/hyperactivity disorder, FASD = fetal alcohol spectrum disorder. 


\section{Completions}

In both groups, we analyzed the number of suicide completions (see Appendix 2 for ICD codes) during the postpartum period (maternal death due to suicide) and after the birth of the index child until the end of the study period.

\section{Statistical analysis}

We modelled adjusted relative rates (RRs) for the outcome variables using generalized linear models with a Poisson or negative binomial distribution. All analyses tested for differences between groups and adjusted for covariates. To model the rates of events for the 2 groups, we created a summary data set for the total number of events (e.g., total number of suicide attempts before birth) for unique strata and the total number of person-years at risk for the strata. We included the log of the total number of person-years as an offset in the model to produce an analysis of rates of events rather than simple counts and to generate estimates of adjusted RRs of events.

We included woman's age at the birth of the index child and socioeconomic status at the birth of the index child as potential covariates in each of the models generating rates of suicide attempts and completions. We defined socioeconomic status according to area-level data on mean household income from census information. Area-level income quintiles were ranked from 1 (lowest) to 5 (highest) on the basis of ranges of mean household income. ${ }^{36}$ For models investigating rates of women who attempted or completed suicide, we adjusted for suicide attempts in the 5 years before the birth of the index child to account for preexisting mental health issues (see Appendix 3, available at www.cmajopen.ca/content/5/3/E646/ suppl/DC1, for ICD codes).

\section{Ethics approval}

Ethics approval was received from the University of Manitoba's Health Research Ethics Board.

\section{Resullts}

The participants consisted of women born between 1946 and 1992, with ages ranging from 14 to 46 years at the birth of the index child (Table 1). Women in the FASD group $(n=702)$ were more likely than those in the comparison group $(n=$ 2097) to be single parents and to be younger at first birth, and tended to have lower socioeconomic status, higher gravidity and higher parity, and a higher proportion had mental disorders (Table 1).

During the study period, 101 women died, of whom 75 (74.2\%) were in the FASD group. The most common cause of death in the FASD group was intentional self poisoning/harm.

\section{Suicide attempts}

There were a total of 10103.40 person-years for the FASD group and 29331.55 person years for the comparison group for the analysis of suicide attempts until the end of the study period. Fewer than 6 women in either group attempted suicide during pregnancy or the postpartum period (the exact numbers are not reported in order to adhere to the MCHP
Table 1 (part 1 of 2): Characteristics of women whose children had FASD and a matched* sample of women whose children did not have FASD

\begin{tabular}{|c|c|c|}
\hline \multirow[b]{2}{*}{ Characteristic } & \multicolumn{2}{|c|}{ No. (\%) of participants $†$} \\
\hline & $\begin{array}{c}\text { FASD group } \\
n=702\end{array}$ & $\begin{array}{c}\text { Comparison } \\
\text { group } \\
n=2097\end{array}$ \\
\hline \multicolumn{3}{|l|}{ Age at birth of index child, yr } \\
\hline Mean \pm SD & $24.43 \pm 6.14$ & $29.24 \pm 5.69$ \\
\hline Range & $14-43$ & $14-46$ \\
\hline$<18$ & $72(10.2)$ & $231(11.0)$ \\
\hline $18-24$ & $333(47.4)$ & $831(39.6)$ \\
\hline $25-29$ & $146(20.8)$ & $525(25.0)$ \\
\hline $30-34$ & $96(13.7)$ & $367(17.5)$ \\
\hline$\geq 35 /$ missing $\ddagger$ & $55(7.8)$ & $143(6.8)$ \\
\hline \multicolumn{3}{|l|}{ Age at birth of first child, yr } \\
\hline$<18$ & 266 (37.9) & $246(11.7)$ \\
\hline $18-24$ & $340(48.4)$ & $854(40.7)$ \\
\hline $25-29$ & $54(7.7)$ & $530(25.3)$ \\
\hline $30-34$ & $29(4.1)$ & $306(14.6)$ \\
\hline$\geq 35 /$ missing $\ddagger$ & $13(1.8)$ & $112(5.3)$ \\
\hline History of teen pregnancy & 266 (37.9) & $246(11.7)$ \\
\hline \multicolumn{3}{|l|}{ Region of residence } \\
\hline Rural & $251(35.8)$ & $764(36.4)$ \\
\hline Urban & $451(64.2)$ & $1333(63.6)$ \\
\hline \multicolumn{3}{|l|}{$\begin{array}{l}\text { Mean household income } \\
\text { quintile }\end{array}$} \\
\hline Q1 (lowest) & $466(64.4)$ & $1398(66.7)$ \\
\hline Q2 & $104(14.8)$ & $312(14.9)$ \\
\hline Q3 & $57(8.1)$ & $171(8.2)$ \\
\hline Q4 & $36(5.1)$ & $108(5.2)$ \\
\hline Q5 (highest) & $26(3.7)$ & $78(3.7)$ \\
\hline Missing & $13(1.8)$ & $30(1.4)$ \\
\hline $\begin{array}{l}\text { Receipt of income } \\
\text { assistance during } 5 \mathrm{yr} \text { before } \\
\text { birth of index child§ }\end{array}$ & $\begin{array}{l}63(18.3) \\
(n=345)\end{array}$ & $\begin{array}{c}98(9.6) \\
(n=1026)\end{array}$ \\
\hline Married at birth of index child & $66(9.4)$ & 773 (36.9) \\
\hline \multicolumn{3}{|l|}{ Gravidity } \\
\hline $0-3$ & $357(50.8)$ & 1966 (93.8) \\
\hline$\geq 4$ & $306(43.6)$ & $113(5.4)$ \\
\hline Missing & $39(5.6)$ & $18(0.8)$ \\
\hline \multicolumn{3}{|l|}{ Parity } \\
\hline $0-3$ & $524(74.6)$ & 2063 (98.4) \\
\hline$\geq 4$ & $139(19.8)$ & $16(0.8)$ \\
\hline Missing & $39(5.6)$ & $18(0.8)$ \\
\hline
\end{tabular}




\begin{tabular}{|c|c|c|}
\hline \multirow[b]{2}{*}{ Characteristic } & \multicolumn{2}{|c|}{ No. (\%) of participants $†$} \\
\hline & $\begin{array}{l}\text { FASD group } \\
n=702\end{array}$ & $\begin{array}{c}\text { Comparison } \\
\text { group } \\
n=2097\end{array}$ \\
\hline $\begin{array}{l}\text { Involvement with Child and } \\
\text { Family Services in } 3 \mathrm{yr} \\
\text { before birth of index child§q }\end{array}$ & $\begin{array}{c}228(66.1) \\
(n=345)\end{array}$ & $\begin{array}{l}136(13.2) \\
(n=1026)\end{array}$ \\
\hline $\begin{array}{l}\text { Diagnosis of psychiatric } \\
\text { disorder in } 3 \mathrm{yr} \text { before birth } \\
\text { of index child**}\end{array}$ & $580(82.6)$ & $566(27.0)$ \\
\hline $\begin{array}{l}\text { Diagnosis of substance } \\
\text { abuset† }\end{array}$ & $179(25.5)$ & $49(2.3)$ \\
\hline $\begin{array}{l}\text { Diagnosis of personality } \\
\text { disordert† }\end{array}$ & $22(3.1)$ & $6(0.3)$ \\
\hline $\begin{array}{l}\text { Diagnosis of mood and } \\
\text { anxiety disordert† }\end{array}$ & $237(33.8)$ & $397(18.9)$ \\
\hline $\begin{array}{l}\text { Diagnosis of } \\
\text { schizophrenia†† }\end{array}$ & $<6 \neq \ddagger$ & $7(0.3)$ \\
\hline $\begin{array}{l}\text { Diagnosis of prenatal } \\
\text { psychological distress§§ }\end{array}$ & $529(75.4)$ & $293(14.0)$ \\
\hline $\begin{array}{l}\text { Diagnosis of postnatal } \\
\text { psychological distress } \uparrow\rceil\end{array}$ & 528 (75.2) & $923(44.0)$ \\
\hline
\end{tabular}

Note: FASD = fetal alcohol spectrum disorder, SD = standard deviation.

*Matched on month of birth of index child, socioeconomic status and region of residence.

†Except where indicated otherwise.

fBecause data were missing for fewer than 6 women, the "missing" category was

combined with the $\geq 35$ years category to ensure that the privacy rules of the

Manitoba Centre for Health Policy were adhered to.

§Because data are available after 1995, the denominator was limited to women

who had babies after 1998 to ensure that 3 years of data were available before

the birth of the child.

IIncludes voluntary or involuntary involvement with Child and Family Services of any child of the mother or the mother herself (if she was under the age of 18 at

the time), including any support services or out-of-home placements.

**Includes substance abuse, personality disorder, mood and anxiety disorder,

schizophrenia, prenatal psychological distress.

†Diagnosis 3 years before birth of index child.

$\ddagger \ddagger$ Suppressed to ensure that the privacy rules of the Manitoba Centre for Health

Policy were adhered to.

$\S \S$ Diagnosis 8 months before birth of index child.

ๆๆDiagnosis 12 months after birth of index child.

privacy policy of suppressing results under 6 events). The FASD group had significantly higher adjusted rates of women who attempted suicide (adjusted RR 4.62 [95\% confidence interval (CI) 2.52-8.43]) and number of attempts (adjusted RR 3.93 [95\% CI 2.30-6.09]) after the postpartum period than the comparison group (Table 2).

\section{Suicide completions}

There were a total of 10694.56 person-years for the FASD group and 29695.65 person years for the comparison group for the analysis of suicide completions until the end of the study period. Compared to women in the comparison group, those in the FASD group had significantly higher adjusted rates of completed suicide after the postpartum period (adjusted RR 6.20 [95\% CI 2.36-16.31]) (Table 2) and had a higher mean age at suicide (37.46 [standard deviation (SD) 6.13] yr, range 29.0-51.5 yr v. 25.75 [SD 5.96] yr, range 20.8$34.6 \mathrm{yr}$ ). The mean length of time between the birth of the index child and suicide in the FASD group was 12.0 (SD 5.13) years, range 4.07-20.19 years.

\section{Interpretation}

The results of our study indicate that women who give birth to children with FASD have increased social complexities, including low socioeconomic status, single parenthood and higher gravidity and parity, and higher rates of mental health disorders, which may place them at higher risk for suicide attempts and completions later in life. These women also have higher rates of all-cause mortality, which highlights the overall high-risk nature of this cohort.

Women in the FASD group did not have an increased risk of death due to suicide during pregnancy and the postpartum period. However, they did have higher rates of prenatal and postpartum psychological distress than the comparison group. Furthermore, a higher proportion of women in the FASD group had mental disorders and prenatal and postpartum psychological distress. These results emphasize the complex relation between mental health disorders, high levels of alcohol consumption and suicide.

Our results are consistent with those of a previous study of women who had given birth to children with FASD conducted in a Northern Plains Indians population, which showed a rate of attempted suicide of $40 \%$ and high rates of intentional and accidental injuries. ${ }^{22}$ Our study contributes to the sparse knowledge base in this area by reinforcing that women who give birth to children with FASD are at increased risk for suicide attempts and completions later in life.

\section{Strengths and limitations}

We used validated population-level data and had a large sample, which enhances the generalizability of our results. Previous investigators used survey and interview data, ${ }^{22}$ which are limited by recall bias. A limitation of our study is the use of a clinically referred sample rather than a population-based sample, which limits the generalizability of the findings. However, the use of this clinically based sample is also a strength, as confirmation of alcohol use during pregnancy at a level associated with teratogenicity (i.e., a diagnosis of FASD) is required as part of the clinical assessment. The FASD group did not include women with alcohol use disorders who did not have a child(ren) referred for FASD assessment. Moreover, although we took great care in excluding all women with possible alcohol use during pregnancy, we cannot be certain that there were no women in our comparison group who had unreported alcohol use during pregnancy.

Suicide attempts are often undercoded in administrative databases, as physicians may list underlying mental illness as the diagnosis or may not accurately chart the occurrence of suicidal behaviour. ${ }^{37}$ There is low sensitivity in the use of these data to track the prevalence of suicide outcomes. Findings from a validation study comparing emergency depart- 
Table 2: Rates of suicide attempts and completions for the 2 groups

\begin{tabular}{|c|c|c|c|}
\hline \multirow[b]{2}{*}{ Outcome } & \multicolumn{2}{|c|}{$\begin{array}{l}\text { Value (crude rate per } \\
1000 \text { person-years) }\end{array}$} & \multirow[b]{2}{*}{ Adjusted RR $(95 \% \mathrm{Cl})$} \\
\hline & FASD group & $\begin{array}{l}\text { Comparison } \\
\text { group }\end{array}$ & \\
\hline \multicolumn{4}{|c|}{$\begin{array}{l}\text { Suicide attempt during } 5 \mathrm{yr} \text { before birth } \\
\text { of index child }\end{array}$} \\
\hline No. of women & $47(13.97)$ & $34(3.27)$ & $5.23(2.63-10.42)^{*}$ \\
\hline No. of attempts & $71(20.76)$ & $48(4.61)$ & $7.05(3.23-4.04)^{*}$ \\
\hline \multicolumn{4}{|c|}{$\begin{array}{l}\text { Suicide attempt after postpartum period } \\
\text { until end of study period }\end{array}$} \\
\hline No. of women & $64(6.33)$ & 39 (1.32) & $4.62(2.53-8.43) \dagger$ \\
\hline No. of attempts & $102(10.10)$ & $104(3.55)$ & $3.92(2.30-6.09) \dagger$ \\
\hline Completed suicide, no. of womenł & $14(1.39)$ & $6(0.20)$ & $6.20(2.36-16.31) \dagger$ \\
\hline \multicolumn{4}{|c|}{$\begin{array}{l}\text { Note: } \mathrm{Cl}=\text { confidence interval, FASD }=\text { fetal alcohol spectrum disorder, } \mathrm{RR}=\text { relative rate. } \\
\text { *Adjusted for age at birth of index child and socioeconomic status. } \\
\text { †Adjusted for age at birth of index child, socioeconomic status and suicide attempts in the } 5 \text { years before birth of index child. } \\
\text { †For entire study period (i.e., } 5 \text { years before birth of index child until Dec. } 1,2013) \text {. }\end{array}$} \\
\hline
\end{tabular}

ment and patient coding for suicide and self-harm attempts versus clinical assessment data suggest that research using hospital and physician claims to identify suicidal outcomes in patients misses up to one-half to two-thirds of outcomes. ${ }^{37}$ Furthermore, only women who received medical care owing to a suicide attempt or whose death had been classified as a suicide would have been included in our study. Administrative data also do not capture suicidal ideation, which results in further underestimation of the burden of suicidal behaviour in this population. Moreover, we do not report the true prevalence of psychiatric disorders in our cohort but, rather, the prevalence of use of physician services for psychiatric illness, as MCHP data are dependent on women's making contact with the health care system. Therefore, our study excludes women with undiagnosed psychiatric disorders and women who had not been assigned relevant diagnostic codes. Mental disorders among women who sought care only from a psychologist or support group would not have been captured.

The administrative data that we used are not collected for research purposes, and there may be unmeasured risk factors that develop or change in the time to suicide that our analysis could not account for. Future research exploring factors that place women at higher risk for suicide that cannot be investigated with administrative data should be conducted. We also could not identify what proportions of women in our study population were from Indigenous communities. Given that suicide is a significant issue in those communities, ${ }^{38,39}$ it would be important to conduct an analysis to describe the burden of suicide among Indigenous women who give birth to children with FASD.

Finally, our results indicate that women with substantial alcohol use during pregnancy are not at higher risk for maternal death (death during the postpartum period) due to suicide. Further analysis with a larger sample should be conducted to confirm this finding, as suicide attempts are difficult to study in shorter periods.

\section{Conclusion}

Women who give birth to children with FASD are at increased risk for suicide attempts and completions. This is likely a reflection of the social complexities faced by this group of women as well as the high rates of mental disorders and high levels of alcohol consumption in this population. Interventions are needed that screen for suicidal behaviour in women who are at high risk to consume alcohol during pregnancy and have mental disorders. Interventions are also needed to provide mental health support for women who have alcohol-exposed fetuses to help prevent suicide later in life.

\section{References}

1. Oates M. Suicide: the leading cause of maternal death. Br 7 Psychiatry 2003; 183:279-81

2. International statistical classification of diseases and related health problems, 10 revision (ICD-10). Geneva: World Health Organization; 2003.

3. Patrick K. It's time to put maternal suicide under the microscope. CMA7 2013:185:1115

4. Darvishi N, Farhadi M, Haghtalab T, et al. Alcohol-related risk of suicidal ideation, suicide attempt, and completed suicide: a meta-analysis. PLoS One 2015;10:e126870.

5. Sung YK, La Flair LN, Mojtabai R, et al. The association of alcohol use disorders with suicidal ideation and suicide attempts in a population-based sample with mood symptoms. Arch Suicide Res 2016;20:219-32.

6. Jané-Llopis E, Matytsina I. Mental health and alcohol, drugs and tobacco: a review of the comorbidity between mental disorders and the use of alcohol, tobacco and illicit drugs. Drug Alcohol Rev 2006;25:515-36.

7. Kennedy MC, Marshall BD, Hayashi K, et al. Heavy alcohol use and suicidal behavior among people who use illicit drugs: a cohort study. Drug Alcohol Depend 2015:151:272-7.

8. Borges G, Loera CR. Alcohol and drug use in suicidal behaviour. Curr Opin Psychiatry 2010;23:195-204.

9. Borges G, Walters EE, Kessler RC. Associations of substance use, abuse, and dependence with subsequent suicidal behavior. Am $\mathcal{F}$ Epidemiol 2000;151: 781-9.

10. Hufford MR. Alcohol and suicidal behavior. Clin Psychol Rev 2001;21:797-811.

11. Astley SJ, Bailey D, Talbot C, et al. Fetal alcohol syndrome (FAS) primary prevention through FAS diagnosis: II. A comprehensive profile of 80 birth mothers of children with FAS. Alcohol Alcohol 2000;3 5:509-19. 
12. May PA, Gossage JP. Maternal risk factors for fetal alcohol spectrum disorders: not as simple as it might seem. Alcohol Res Health 2011;34:15-26.

13. May PA, Gossage JP, Marais AS, et al. Maternal risk factors for fetal alcohol syndrome and partial fetal alcohol syndrome in South Africa: a third study. Alcohol Clin Exp Res 2008;32:738-53.

14. Skagerström J, Alehagen S, Häggström-Nordin E, et al. Prevalence of alcohol use before and during pregnancy and predictors of drinking during pregnancy: a cross sectional study in Sweden. BMC Public Health 2013;13:780.

15. Skagerstróm J, Chang G, Nilsen P. Predictors of drinking during pregnancy: a systematic review. 7 Womens Health (Larchmt) 2011;20:901-13.

16. Viljoen D, Croxford J, Gossage JP, et al. Characteristics of mothers of children with fetal alcohol syndrome in the Western Cape Province of South Africa: a case control study. I Stud Alcohol 2002;63:6-17.

17. Bolton JM, Pagura J, Enns MW, et al. A population-based longitudinal study of risk factors for suicide attempts in major depressive disorder. 7 Psychiatr Res 2010;44:817-26.

18. Randall JR, Walld R, Finlayson G, et al. Acute risk of suicide and suicide attempts associated with recent diagnosis of mental disorders: a populationbased, propensity score-matched analysis. Can 7 Psychiatry 2014;59:531-8.

19. Wang Y, Sareen J, Afifi TO, et al. A population-based longitudinal study of recent stressful life events as risk factors for suicidal behavior in major depressive disorder. Arch Suicide Res 2015;19:202-17.

20. Nock MK, Hwang I, Sampson N, et al. Cross-national analysis of the associations among mental disorders and suicidal behavior: findings from the WHO World Mental Health Surveys. PLoS Med 2009;6:e1000123.

21. Kvigne VL, Leonardson GR, Borzelleca J, et al. Characteristics of mothers who have children with fetal alcohol syndrome or some characteristics of fetal alcohol syndrome. 7 Am Board Fam Pract 2003;16:296-303.

22. Kvigne VL, Leonardson GR, Borzelleca J, et al. Alcohol use, injuries, and prenatal visits during three successive pregnancies among American Indian women on the Northern Plains who have children with fetal alcohol syndrome or incomplete fetal alcohol syndrome. Matern Child Health 7 2008;12 (Suppl 1):37-45.

23. Poole N, Greaves L. Alcohol use during pregnancy in Canada: how policy moments can create opportunities for promoting women's health. Can $\mathcal{F}$ Public Health 2013;104:e170-2.

24. Gentile S. Suicidal mothers. 7 Inj Violence Res 2011;3:90-7.

25. Singal D, Brownell M, Hanlon-Dearman A, et al. Manitoba mothers and fetal alcohol spectrum disorders study (MBMomsFASD): protocol for a populationbased cohort study using linked administrative data. BM7 Open 2016;6:e013330.

26. Brownell MD, Roos NP, Roos LL. Monitoring health reform: a report card approach. Soc Sci Med 2001;52:657-70.

27. Jutte DP, Roos LL, Brownell MD. Administrative record linkage as a tool for public health research. Annu Rev Public Health 2011;32:91-108.

28. Kozyrskyj AL, Mustard CA. Validation of an electronic, population-based prescription database. Ann Pharmacother 1998;32:1152-7.

29. Robinson JR, Young TK, Roos LL, et al. Estimating the burden of disease. Comparing administrative data and self-reports. Med Care 1997;35:932-47.

30. Roos LL, Gupta S, Soodeen RA, et al. Data quality in an information-rich environment: Canada as an example. Can f Aging 2005;24(Suppl 1):153-70.

31. Roos LL, Menec V, Currie RJ. Policy analysis in an information-rich environment. Soc Sci Med 2004;58:2231-41.

32. Roos LL, Nicol JP. A research registry: uses, development, and accuracy. 7 Clin Epidemiol 1999;52:39-47.

33. Roos LL Jr, Nicol JP, Cageorge SM. Using administrative data for longitudinal research: comparisons with primary data collection. 7 Chronic Dis 1987; 40:41-9.
34. Burger PH, Goecke TW, Fasching PA, et al. How does maternal alcohol consumption during pregnancy affect the development of attention deficit/ hyperactivity syndrome in the child? [article in German]. Fortschr Neurol Psychiatr 2011;79:500-6.

35. Infante MA, Moore EM, Nguyen TT, et al. Objective assessment of ADHD core symptoms in children with heavy prenatal alcohol exposure. Physiol Behav 2015;148:45-50.

36. Profile of the population, 2001 census. Statistics Canada Data Liberation Initiative table name 95F0495XCB01002-Man.ivt. Ottawa: Statistics Canada; 2003.

37. Randall JR, Roos LL, Lix LM, et al. Emergency department and inpatient coding for self-harm and suicide attempts: validation using clinician assessment data. Int 7 Methods Psychiatr Res 2017 Feb. 24 [Epub ahead of print]. doi: $10.1002 / \mathrm{mpr} .1559$.

38. Elias B, Mignone J, Hall M, et al. Trauma and suicide behaviour histories among a Canadian indigenous population: an empirical exploration of the potential role of Canada's residential school system. Soc Sci Med 2012;74: 1560-9.

39. Webster PC. Canada's Indigenous suicide crisis. Lancet 2016;387:2494.

Affiliations: Department of Community Health Sciences and the Manitoba Centre for Health Policy (Singal, Brownell, Chateau, Wall-Wieler, Roos) and Department of Pediatrics and Child Health (Longstaffe, Hanlon-Dearman), Max Rady College of Medicine, Rady Faculty of Health Sciences, University of Manitoba, Winnipeg, Man.

Contributors: Deepa Singal and Marni Brownell conceived the study. Deepa Singal collected and analyzed the data, and Elizabeth Wall-Wieler assisted with data analysis. Marni Brownell, Leslie Roos, Sally Longstaffe, Ana Hanlon-Dearman and Dan Chateau interpreted the data. All of the authors contributed to the design of the study, participated in the preparation of the manuscript, revised the manuscript critically for important intellectual content, approved the final version to be published and agreed to act as guarantors of the work.

Funding: This work was supported by Research Manitoba, the Evelyn Shapiro Award for Health Services Research and the Canadian Foundation on Fetal Alcohol Research.

Acknowledgements: The authors acknowledge the Manitoba Centre for Health Policy for use of data contained in the Population Health Research Data Repository under project 2013-036 (HIPC\#2013/201420). Data used in this study are from the Population Health Research Data Repository and were derived from data provided by the following organizations: the Manitoba FASD Centre, the Winnipeg Regional Health Authority, Healthy Child Manitoba, Manitoba Families and the Manitoba Education and Training Department. The results and conclusions are those of the authors, and no official endorsement by the Manitoba Centre for Health Policy, Manitoba Health, Seniors and Active Living or other data providers is intended or should be inferred.

Supplemental information: For reviewer comments and the original submission of this manuscript, please see www.cmajopen.ca/content $/ 5 / 3$ / E646/suppl/DC1 